\title{
Trends in Gabapentin Prescribing in a Commercially Insured U.S. Adult Population, 2009-2016
}

\author{
Nathan J. Pauly, PhD; Chris Delcher, PhD; Svetla Slavova, PhD; Eric Lindahl, BS;
} Jeff Talbert, PhD; and Patricia R. Freeman, PhD

\begin{abstract}
BACKGROUND: Gabapentin is prescribed for a variety of conditions and is often used off label. It is important to understand the prevalence of gabapentin prescribing and the characteristics of individuals who are prescribed gabapentin, given increasing concern regarding its potential for misuse.
\end{abstract}

OBJECTIVES: To (a) examine state- and region-level prevalence and trends in gabapentin prescribing from 2009 to 2016 and (b) characterize demographic and clinical characteristics of individuals prescribed gabapentin in a nationwide population of commercially insured adults.

METHODS: This retrospective, longitudinal study examined trends in gabapentin prescribing from 2009 to 2016 . The study population included individuals aged 18-64 years who were enrolled in a commercial insurance plan at any point from 2009 to 2016. Individuals who were prescribed gabapentin were defined as beneficiaries with at least 1 gabapentin prescription claim in a calendar year (CY). A cross-sectional descriptive analysis was performed to examine differences in demographic and clinical characteristics of individuals prescribed or not prescribed gabapentin in CY 2016.

RESULTS: The prevalence of gabapentin prescribing nearly doubled from 2009 to 2016. During this time, gabapentin prescribing increased in every state (range: 44\%-179\%). State-specific prevalence rates in 2016 varied from 12.7 to 43.9 per 1,000 beneficiaries. Overall, $2.7 \%$ of beneficiaries filled $\geq 1$ gabapentin prescription in 2016. Individuals prescribed gabapentin were more likely to fill opioid prescriptions $(60.8 \%$ vs. $16.5 \%, P<0.01)$; reside in the South $(53.7 \%$ vs. $47 \%, P<0.01)$; be female $(62.5 \%$ vs. $52.3 \%$, $P<0.01)$; and be aged $55-64$ years $(41.7 \%$ vs. $21.2 \%, P<0.01)$ compared with the comparator. Individuals who were prescribed gabapentin also had significantly higher rates of seizure disorders, neuropathic pain, mental health disorders, substance use disorders, and diabetes.

CONCLUSIONS: The prevalence of gabapentin prescribing among a U.S. privately insured population has increased steadily in recent years. Additional research should examine coprescribing of gabapentin in the context of the opioid epidemic.

J Manag Care Spec Pharm. 2020;26(3):246-52

Copyright $\odot 2020$, Academy of Managed Care Pharmacy. All rights reserved.

\section{What is already known about this subject}

The prescribing of gabapentin is prevalent, and reports suggest that it is frequently prescribed off label.

Concerns over gabapentin's safety and efficacy have led some states to label gabapentin as a "drug of concern."

\section{What this study adds}

The prevalence of gabapentin prescribing increased in every U.S state from 2009 to 2016.

Individuals who were prescribed gabapentin had significantly higher rates of a diagnosed substance use disorder and coprescriptions of opioids compared with individuals who were not prescribed gabapentin.

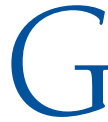
abapentin, a prescription medication in the gabapentinoid class, is indicated in the United States for treatment of partial-onset seizures and postherpetic neuralgia. ${ }^{1}$ In 2016, 64 million gabapentin prescriptions were dispensed in the United States, making it the tenth most commonly prescribed medication. ${ }^{2}$ Originally approved by the U.S. Food and Drug Administration (FDA) in 1993, gabapentin was perceived to have a low abuse potential and was therefore approved as a nonscheduled medication. ${ }^{1}$ Due, in part, to its favorable safety profile, gabapentin has become a prevalent off-label option for a variety of medical conditions, including other neuropathic pain conditions, ${ }^{3,4}$ hot flashes, ${ }^{5,6}$ postoperative nausea/vomiting, ${ }^{7,8}$ postoperative pain, ${ }^{9,10}$ alcohol dependence/withdrawal, ${ }^{11,12}$ and other substance use disorders (SUD), ${ }^{13-17}$ with estimates of offlabel prescribing as high as $95 \% .^{18}$

Data on efficacy of gabapentin for off-label uses, however, are limited, at best. Peckham et al. (2018) conducted a comprehensive review of the relevant data on the efficacy of gabapentin for unapproved indications and found evidence that weakly supports gabapentin's effectiveness for several conditions but cautions that most of the evidence for off-label use is limited to relatively few, low-quality studies. ${ }^{19}$ A recent Cochrane review of gabapentin for chronic neuropathic pain in adults found that while gabapentin is effective for postherpetic neuralgia and peripheral diabetic neuropathy, there is limited evidence of effectiveness for other types of neuropathic pain. The authors concluded that for these 2 types of neuropathic pain, the use of gabapentin as a first-line agent, as recommended by current guidelines, is supported. ${ }^{20}$

Gabapentin misuse and diversion were first reported in the literature in 1997. ${ }^{21}$ Since that time, concern over the abuse potential of gabapentin has increased, but the drug remains federally nonscheduled. ${ }^{22}$ A 2016 systematic review by 
Smith et al. estimated the prevalence of gabapentin misuse in the general population to be $1 \%$, with increased prevalence within populations who abused opioids and among individuals with gabapentin prescriptions. ${ }^{23}$ A 2017 systematic review estimated the prevalence of gabapentin abuse in the general population at $1.6 \%$, with wide-ranging prevalence estimates from 3\%-68\% among those who misuse opioids. ${ }^{24}$

Recent evidence suggests that use of gabapentin concurrently with opioids increases the risk for adverse medical events and fatal overdoses. ${ }^{25}$ For example, an analysis of regional poison control center data found that exposures involving gabapentin coingested with other drugs resulted in a greater rate of moderate to major medical events compared with gabapentin-only exposures. ${ }^{26}$ Toxicology data from some states have also shown increased gabapentin involvement in drug overdose deaths. In Kentucky, approximately $41 \%$ of fatal polysubstance overdoses were positive for gabapentin in 2015. ${ }^{27}$ Further, a recent analysis of gabapentin-related fatalities in Virginia found that $77.6 \%$ of cases where gabapentin was the underlying cause of death also had at least 1 opioid present. ${ }^{28}$ As a result of these safety concerns, the prescribing of gabapentin is under increased scrutiny, with state policymakers considering a variety of regulatory approaches to mitigate the potential for gabapentinrelated harm. As of August 2018, 7 states (Massachusetts, Minnesota, North Dakota, Ohio, Virginia, West Virginia, and Wyoming) have labeled gabapentin a "drug of concern" that is reportable to the state prescription drug monitoring program (PDMP), and 2 states (Kentucky and Tennessee) have reclassified gabapentin as a Schedule V controlled substance. ${ }^{22}$

Concern over gabapentin safety and efficacy is increasing, yet few studies have examined the prevalence of gabapentin prescribing and/or characterized the clinical and demographic profiles for those receiving a gabapentin prescription. We are aware of only 1 study that has examined trends in gabapentin prescribing in the United States. Using data from the Medical Expenditure Panel Survey, Johansen (2018) found that selfreported gabapentin use more than tripled from 2002 to 2015 and that $52.6 \%$ of individuals reporting gabapentin use also reported using more than 2 opioid prescriptions or a benzodiazepine prescription in the same year. ${ }^{29}$ In the present study, using a nationwide population of commercially insured adults, we examined state- and region-level prevalence and percentage changes in gabapentin prescribing between 2009 and 2016 and characterized select demographic and clinical characteristics of individuals who were prescribed gabapentin.

\section{Methods}

\section{Data Source}

Data on the prescribing of gabapentin among a commercially insured population aged 18-64 years were obtained from the IBM Marketscan Commercial Claims and Encounters Database. IBM Marketscan offers fully integrated pharmaceutical and medical administrative claims data with relevant health plan enrollment and demographic data. These data cover commercially insured individuals and their dependents in all U.S. states and include all provider, facility, and pharmaceutical claims for eligible beneficiaries. The database captures administrative claims for approximately 20-30 million distinct individuals enrolled at any point in a given year.

\section{Study Design}

Individuals were classified as having been prescribed gabapentin if they had at least 1 gabapentin prescription claim during a calendar year (CY). Gabapentin prescriptions were identified using Generic Product Identifier (GPI) codes. This study used a retrospective, cross-sectional design to examine the prevalence and percentage changes in the prevalence of gabapentin prescribing from 2009 to 2016 in a population of commercially insured adults. The prevalence of gabapentin prescribing was calculated as the number of individuals with a gabapentin prescription claim per 1,000 distinct beneficiaries observed in each state-year. We did not include pregabalin in the study because pregabalin is already a controlled substance and is used much less frequently than gabapentin. ${ }^{29}$ All individuals aged 18-64 years who were enrolled at any point from January 1 , 2009, to December 31, 2016, with pharmacy and medical benefits were included in the study population. This study solely relied on deidentified administrative claims data and thus was deemed exempt from review by the institutional review board at the University of Kentucky.

In addition to the analysis describing longitudinal trends in gabapentin prescribing at the state level, this study also employed a descriptive cross-sectional analysis examining demographic and clinical characteristics of individuals prescribed gabapentin in CY 2016. We used CY 2016 for this cross-sectional analysis because it was the most recent year of data available. Demographic characteristics available for analysis included state of residence; U.S. Census region (South, Northeast, West, Midwest); age group (18-34, 35-44, 45-54, and 55-64 years); and sex (male, female). Clinical characteristics examined included opioid prescription claims and diagnoses related to seizure disorders, mental health conditions, neuropathic pain, diabetes, and SUD.

Opioid analgesic prescriptions were identified using GPI codes beginning with 65 , and beneficiaries were classified as individuals who were prescribed opioids if they filled any opioid analgesic prescriptions in CY 2016. Comorbidities of interest were identified using Clinical Classification Software from the Agency for Healthcare Research and Quality, as well as International Classification of Diseases, Ninth/Tenth Revision, Clinical Modification codes. ${ }^{30}$ Individuals were identified with an existing comorbidity if they had at least 1 claim with a relevant diagnosis code at any point in CY 2016. 


\section{Statistical Analysis}

Record-level patient claims were aggregated into prevalence rates at the state-year level to describe trends in gabapentin prescribing in this population. Demographic and clinical differences between individuals receiving gabapentin or not in 2016 were assessed using chi-square tests and t-tests where appropriate. All analyses were conducted using SAS version 9.4 (SAS Institute, Cary NC).

\section{Results}

The prevalence of gabapentin prescribing in this commercially insured population increased from 2009 to 2016. Nationwide, the prevalence of gabapentin prescribing more than doubled from 13.3 recipients per 1,000 beneficiaries in 2009 to 27.1 recipients per 1,000 in 2016. Every state experienced an increase in the prevalence of gabapentin prescribing over this time period. Figure 1 displays the eligible beneficiary population, annual prevalence, and percent change in the prevalence of gabapentin prescribing observed in each state from 2009 to 2016.

In 2016, the prevalence of gabapentin prescribing ranged from a high of 43.9 recipients per 1,000 beneficiaries in Kentucky to a low of 12.7 recipients per 1,000 beneficiaries in Washington DC. South Dakota experienced the greatest relative increase (179.4\%) in the prevalence of gabapentin prescribing, but Connecticut experienced the smallest increase (44.1\%) from 2009 to 2016. Interactive data visualizations presenting the state-year prevalence of gabapentin prescribing, stratified by select demographic characteristics, may be found as supplemental material online at: https://pharmacy.uky.edu/ trends-in-gabapentin-use.

Demographic and clinical characteristics of individuals who were and were not prescribed gabapentin in 2016 are displayed in Table 1. Overall, 536,488 (2.7\%) beneficiaries filled at least 1 gabapentin prescription in 2016. All differences tested were significant at $P<0.0001$. The group of individuals prescribed gabapentin included a significantly greater proportion of individuals who resided in the South $(53.7 \%$ vs. $47.0 \%)$, were female (62.5\% vs. $52.3 \%$ ), and were aged $55-64$ years ( $41.7 \%$ vs. $21.2 \%$ ) compared with individuals who were not prescribed gabapentin.

As expected, the prevalence of opioid prescribing was significantly higher among individuals who were prescribed gabapentin, with $60.8 \%$ of individuals who were prescribed gabapentin filling at least 1 opioid prescription in 2016 compared with only $16.5 \%$ among individuals who were not prescribed gabapentin. Furthermore, individuals who were prescribed gabapentin and were coprescribed opioids, filled on average over twice as many opioid prescriptions for nearly double the average days supply compared with individuals who were not prescribed gabapentin who filled opioid prescriptions.
Also, the population of individuals who were prescribed gabapentin observed in this study had significantly higher rates of comorbidities compared with individuals who were not prescribed gabapentin. As expected, individuals who were prescribed gabapentin had over 6 times the rate of neuropathic pain disorders. Notably, individuals who were prescribed gabapentin had over 3 times the rate of diabetes (303.9 vs. 101.1 per 1,000) and over 4 times the rate of SUD (162.8 vs. 37.3 per $1,000)$ compared with individuals who were not prescribed gabapentin.

\section{Discussion}

The prevalence of gabapentin prescribing increased in every year, state, and demographic group examined between 2009 and 2016 in the commercially insured population observed in this study. Our finding, based on filled prescription claims, is consistent with self-reported gabapentin use that tripled between 2002 and $2015^{29}$ and with other U.S. prescribing data that indicate a 2.3-fold increase in the number of gabapentin prescriptions dispensed in retail, mail-order, and long-term care pharmacies between 2010 and 2017.,31 The increase in the prevalence of gabapentin prescribing may, in part, be reflective of the prescriber perception that gabapentin was a safer and more effective nonopioid, first-line pain medication in the context of the current opioid overdose epidemic. ${ }^{32}$

In addition, this study found that opioid prescribing rates were significantly higher among individuals who were prescribed gabapentin. Nine of the 10 states (Alabama, Arkansas, Tennessee, Mississippi, Louisiana, Oklahoma, Kentucky, West Virginia, and South Carolina) with the highest prevalence of gabapentin prescribing in 2016 observed in our study were also in the top 10 states in terms of estimated rates of opioid prescriptions per 100 residents in the general population in 2016. (Note: South Carolina was one of the top 10 states in terms of gabapentin use in 2016; however, we were unable to present individual results from this state in Figure 1). ${ }^{33}$ As states have implemented opioid use policies, such as mandatory use of prescription drug monitoring programs before prescribing opioids and limits on the days supply and morphine milligram equivalents of initial opioid prescriptions, ${ }^{34}$ prescribers may be using gabapentin as a nonopioid adjunctive therapy for chronic pain. Another possible explanation for this observation is that the correlation between gabapentin and opioid prescribing may be because gabapentin is used to treat neuropathic pain, which may also be treated with opioid analgesics as secondline therapy. ${ }^{35}$

Recent qualitative reports suggest that gabapentin may be misused by individuals with opioid use disorder in lieu of or to potentiate the effects of opioids. ${ }^{36-39}$ The Centers for Medicaid \& Medicare Services (CMS) recently identified gabapentin as an opioid potentiator in official documents in conjunction with an analysis examining gabapentin and opioid 
FIGURE 1 State-Level Prevalence (Rank Ordered in 2016) and Percentage of Changes in Prevalence of Gabapentin Prescribing from January 1, 2009, to December 31, 2016

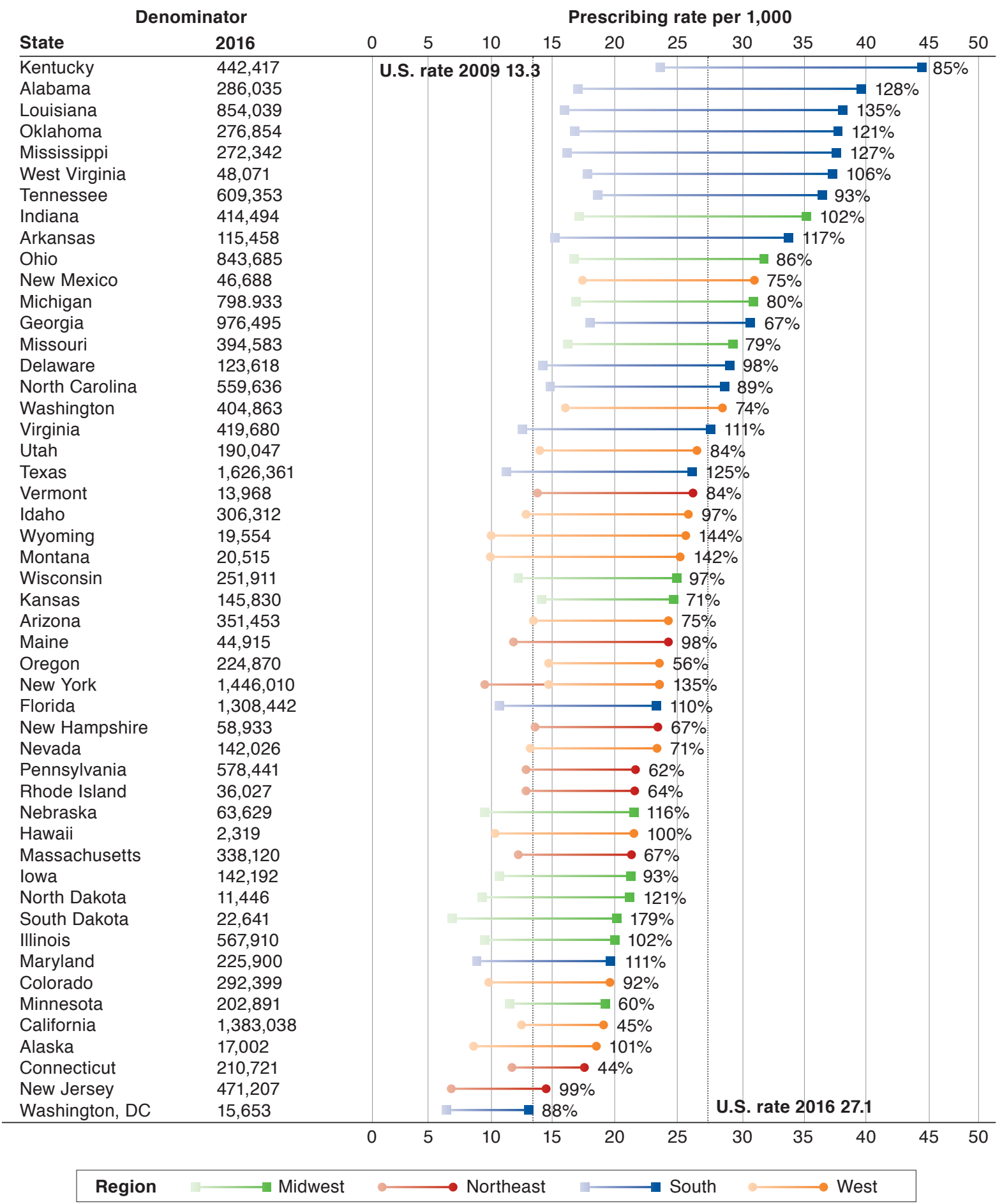

Note: South Carolina was included in the analysis; however, we were prohibited from presenting state-specific results from South Carolina in this figure. 
Trends in Gabapentin Prescribing in a Commercially Insured U.S. Adult Population, 2009-2016

\begin{tabular}{|c|c|c|}
\hline & $\begin{array}{l}\text { Individuals Prescribed Gabapentin, } \mathrm{n}(\%) \\
(\mathrm{n}=536,488)\end{array}$ & $\begin{array}{l}\text { Individuals Not Prescribed Gabapentin, } n(\%) \\
(n=19,266,873)\end{array}$ \\
\hline \multicolumn{3}{|l|}{ Region $(\mathrm{N}=19,803,361)$} \\
\hline Northeast & 66,625 & $3,131,730$ \\
\hline Midwest & 106,604 & $3,753,529$ \\
\hline South & 287,910 & $9,055,912$ \\
\hline West & 75,349 & $3,325,702$ \\
\hline \multicolumn{3}{|l|}{ Sex } \\
\hline Male & 201,077 & $9,190,284$ \\
\hline Female & 335,411 & $10,076,589$ \\
\hline \multicolumn{3}{|l|}{ Age group, years } \\
\hline $18-34$ & 61,652 & $7,030,865$ \\
\hline $35-44$ & 88,285 & $3,910,073$ \\
\hline $45-54$ & 162,911 & $4,247,578$ \\
\hline $55-64$ & 223,640 & $4,078,357$ \\
\hline \multicolumn{3}{|l|}{ Opioid use } \\
\hline Yes & 326,098 & $3,187,077$ \\
\hline No & 210,390 & $16,079,796$ \\
\hline Mean number prescriptions & $(7.0)$ & $(4.0)$ \\
\hline Mean days supply & (11.8) & $(9.2)$ \\
\hline \multicolumn{3}{|c|}{ Comorbidities, rates per 1,000} \\
\hline Seizure disorders & 25.9 & 6.3 \\
\hline Neuropathic pain & 506.6 & 80.1 \\
\hline Mental health disorders & 395.4 & 144.7 \\
\hline Substance use disorder & 162.8 & 37.3 \\
\hline Diabetes & 303.9 & 101.1 \\
\hline
\end{tabular}

coprescribing. CMS found that gabapentin prescribing, particularly at high dosages among opioid users, may result in increased risk of adverse events. In response to this finding, CMS added a concurrent opioid-gabapentinoid flag to the Medicare Part D overutilization management tool. ${ }^{40}$

Consistent with the FDA-approved indications and current clinical guidelines for gabapentin prescribing, ${ }^{41}$ the rates of seizure disorders, diabetes, and neuropathic pain diagnoses were significantly higher among individuals who were prescribed gabapentin. Interestingly, we found that the rate of SUD was over 4 times higher among individuals who were prescribed gabapentin. While this finding is consistent with off-label use as a treatment for SUD, ${ }^{11-17}$ it may also be a reflection of prescriber reluctance to use opioids for pain treatment in individuals with a history of SUD. ${ }^{32}$

Interestingly, the state-year prevalence of gabapentin prescribing observed in this commercially insured population does not align with the states that have taken regulatory actions to increase gabapentin monitoring. Of the top 10 states with the highest prevalence of gabapentin prescribing in 2016, only 4 to date (Kentucky, Ohio, Tennessee, and West Virginia) have implemented gabapentin monitoring by labeling the medication a Schedule V controlled substance or requiring reporting to the state PDMP. ${ }^{22}$ Further, of the 10 states that experienced the greatest percent increase in the prevalence of gabapentin prescribing from 2009 to 2016, only 2 to date have implemented gabapentin monitoring (Wyoming and North Dakota). ${ }^{22}$ These observations suggest that policymakers in many states are either unaware, or unconcerned, about the high prevalence and rapid increases in gabapentin use. Prescribing data at the state level that are independent of payer type are needed to better understand the overall prevalence of gabapentin prescribing and better inform policymakers who are considering the need for gabapentin control measures.

\section{Limitations}

This study is subject to several limitations. First, individuals who were prescribed gabapentin in this study were identified from pharmacy claims for gabapentin prescriptions. Using these data alone, we were unable to verify that individuals receiving a gabapentin prescription at the pharmacy actually used the medication. However, this limitation is present in any pharmacoepidemiological analysis conducted using administrative claims data. 
Second, the administrative claims data used in this study did not include data from individuals who paid cash for gabapentin prescriptions, so our estimate of gabapentin use in this population may be considered a conservative estimate. Third, these results are only representative of a U.S. commercially insured and employed population and may not be representative of the U.S. population at large.

Finally, the results presented here are a simple descriptive assessment of trends in gabapentin prescribing. Future research using more robust statistical analyses are necessary to assess predictors and outcomes associated with gabapentin prescribing.

\section{Conclusions}

The prescribing of gabapentin among a privately insured population is increasing in the United States. This study adds several novel findings to the existing literature that has examined this trend, most notably in describing the geographic variation in the prevalence of gabapentin prescribing and the clinical characteristics of individuals who are prescribed gabapentin. Additional research is needed to more carefully examine the role of gabapentin in the ongoing opioid epidemic.

\section{Authors}

NATHAN J. PAULY, PhD, Department of Health Policy, Management, and Leadership, West Virginia University School of Public Health, Morgantown, and SVETLA SLAVOVA, PhD, Department of Biostatistics, University of Kentucky College of Public Health, Lexington. CHRIS DELCHER, PhD; ERIC LINDAHL, BS; JEFF TALBERT, PhD; and PATRICIA R. FREEMAN, PhD, Institute for Pharmaceutical Outcomes and Policy, University of Kentucky College of Pharmacy, Lexington.

AUTHOR CORRESPONDENCE: Nathan J. Pauly, PhD, Department of Health Policy, Management, and Leadership, West Virginia University School of Public Health, P.O. Box 9190, Morgantown, WV 26505. Tel.: 304.356.4929; E-mail: Nathan.pauly@hsc.wvu.edu.

\section{DISCLOSURES}

The project described in this study was supported by the NIH National Center for Advancing Translational Sciences through grant number UL1TR001998. This study was also partially supported by grant number 2017-PM-BX-K026 (Data-Driven Responses to Prescription Drug Misuse in Kentucky) awarded by the Bureau of Justice Assistance. Viewpoints or opinions in this document are those of the authors and do not necessarily represent the official position or policies of the U.S. Department of Justice or the official views of the NIH. The authors do not have any conflicts of interest to report.

Portions of this study have been previously presented in poster presentations at the 2019 Academy Health Annual Research Meeting; June 2-4, 2019; Washington, DC, and the 2019 University of Kentucky Substance Use Research Day; March 3, 2019; Lexington, KY.

\section{ACKNOWLEDGMENTS}

The authors acknowledge Eugene Shin for his assistance with creating the interactive data visualizations.

\section{REFERENCES}

1. Neurontin (gabapentin) capsules, for oral use. Parke-Davis, division of Pfizer. Revised October 2017. Available at: https://www.accessdata.fda.gov/ drugsatfda_docs/label/2017/020235s064_020882s047_021129s046lbl.pdf. Accessed January 27, 2020.

2. IQVIA Institute for Human Data Science. Medicine use and spending in the U.S.: a review of 2017 and outlook to 2022. April 19, 2018. Available at: https://www.iqvia.com/institute/reports/medicine-use-and-spending-in-theus-review-of-2017-outlook-to-2022. Accessed January 27, 2020.

3. Serpell MG. Gabapentin in neuropathic pain syndromes: a randomised, double-blind, placebo-controlled trial. Pain. 2002;99(3):557-66.

4. Moore A, Derry S, Wiffen P. Gabapentin for chronic neuropathic pain. JAMA. 2018;319(8):818-19.

5. Pandya KJ, Morrow GR, Roscoe JA, et al. Gabapentin for hot flashes in 420 women with breast cancer: a randomised double-blind placebo-controlled trial. Lancet. 2005;366(9488):818-24.

6. Guttuso T, Kurlan R, McDermott MP, Kieburtz K. Gabapentin's effects on hot flashes in postmenopausal women: a randomized controlled trial. Obstet Gynecol. 2003;101(2):337-45.

7. Grant M, Lee H, Page A, Hobson D, Wick E, Wu C. The effect of preoperative gabapentin on postoperative nausea and vomiting. Anesth Analg 2016;122(4):976-85

8. Guttuso T. Gabapentin's anti-nausea and anti-emetic effects: a review. Exp Brain Res. 2014;232(8):2535-39.

9. Doleman B, Heinink TP, Read DJ, Faleiro RJ, Lund JN, Williams JP. A systematic review and meta-regression analysis of prophylactic gabapentin for postoperative pain. Anaesthesia. 2015;70(10):1186-204.

10. Peng PW, Wijeysundera DN, Li CC. Use of gabapentin for perioperative pain control-meta-analysis. Pain Res Manag. 2007;12(2):85-92.

11. Mason BJ, Quello S, Goodell V, Shadan F, Kyle M, Begovic A. Gabapentin treatment for alcohol dependence: a randomized clinical trial. JAMA Intern Med. 2014;174(1):70-77.

12. Myrick H, Malcolm R, Randall PK, et al. A double-blind trial of gabapentin versus lorazepam in the treatment of alcohol withdrawal. Alcohol Clin Exp Res. 2009;33(9):1582-88

13. Gentry JR, Hill C, Malcolm R. New anticonvulsants: a review of applications for the management of substance abuse disorders. Ann Clin Psychiatry. 2002;14(4):233-45.

14. Sherman BJ, McRae-Clark AL. Treatment of cannabis use disorder: current science and future outlook. Pharmacother J Hum Pharmacol Drug Ther. 2016;36(5):511-35.

15. Mariani JJ, Malcolm RJ, Mamczur AK, et al. Pilot trial of gabapentin for the treatment of benzodiazepine abuse or dependence in methadone maintenance patients. Am J Drug Alcohol Abuse. 2016;42(3):333-40.

16. Bisaga A, Aharonovich E, Garawi F, et al. A randomized placebocontrolled trial of gabapentin for cocaine dependence. Drug Alcohol Depend. 2006;81(3):267-74.

17. Sanders NC, Mancino MJ, Gentry WB, et al. Randomized, placebo-controlled pilot trial of gabapentin during an outpatient, buprenorphine-assisted detoxification procedure. Exp Clin Psychopharmacol. 2013;21(4):294-302.

18. Radley DC, Finkelstein SN, Stafford RS. Off-label prescribing among office-based physicians. Arch Intern Med. 2006;166(9):1021-26. 
19. Peckham AM, Evoy KE, Ochs L, Covvey JR. Gabapentin for off-label use: evidence-based or cause for concern? Subst Abuse. 2018;12:1-8. Available at: https://journals.sagepub.com/doi/10.1177/1178221818801311. Accessed January 27,2020

20. Wiffen PJ, Derry S, Bell RF, et al. Gabapentin for chronic neuropathic pain in adults. Cochrane Database Syst Rev. 2017;6:CD007938.

21. Markowitz JS, Finkenbine R, Myrick H, King L, Carson WH. Gabapentin abuse in a cocaine user. J Clin Psychopharmacol. 1997;17(5):423-24.

22. Peckham AM, Ananickal MJ, Sclar DA. Gabapentin use, abuse, and the US opioid epidemic: the case for reclassification as a controlled substance and the need for pharmacovigilance. Risk Manag Healthc Policy. 2018;11:109-16.

23. Smith RV, Havens JR, Walsh SL. Gabapentin misuse, abuse and diversion: a systematic review. Addiction. 2016;111(7):1160-74.

24. Evoy KE, Morrison MD, Saklad SR. Abuse and misuse of pregabalin and gabapentin. Drugs. 2017;77(4):403-26.

25. Gomes T, Juurlink DN, Antoniou T, Mamdani MM, Paterson JM, van den Brink W. Gabapentin, opioids, and the risk of opioid-related death: a population-based nested case-control study. PLoS Med. 2017; 14(10):e1002396.

26. Faryar KA, Webb AN, Bhandari B, Price TG, Bosse GM. Trending gabapentin exposures in Kentucky after legislation requiring use of the state prescription drug monitoring program for all opioid prescriptions. Clin Toxicol (Phila). 2019;57(6):398-403

27. Slavova S, Miller A, Bunn TL, et al. Prevalence of gabapentin in drug overdose postmortem toxicology testing results. Drug Alcohol Depend. 2018;186:80-85

28. Tharp AM, Hobron K, Wright T. Gabapentin-related deaths: patterns of abuse and postmortem levels. J Forensic Sci. 2019;64(4):1105-11.

29. Johansen ME. Gabapentinoid use in the United States 2002 through 2015. JAMA Intern Med. 2018;178(2):292-94.

30. Healthcare Cost and Utilization Project (HCUP). Clinical Classifications Software (CCS) for ICD-10-PCS (beta version). October 2018. Available at: https://www.hcup-us.ahrq.gov/toolssoftware/ccs10/ccs10.jsp. Accessed January 27, 2020.
31. IMS Institute for Healthcare Informatics. Medicines use and spending shifts: a review of the use of medicines in the U.S. in 2014. April 2015. Available at: https://www.iqvia.com/-/media/iqvia/pdfs/institute-reports/ medicines-use-and-spending-shifts-in-the-us-in-2014.pdf. Accessed January 27, 2020.

32. Goodman CW, Brett AS. Gabapentin and pregabalin for pain - is increased prescribing a cause for concern? N Engl J Med. 2017;377(5):411-14.

33. Centers for Disease Control and Prevention. U.S. opioid prescribing rate maps. Opioid overdose. October 29, 2018. Available at: https://www.cdc.gov/ drugoverdose/maps/rxrate-maps.html. Accessed January 27, 2020.

34. National Conference of State Legislatures. Prescribing policies: states confront opioid overdose epidemic. June 30, 2019. Available at: http://www. ncsl.org/research/health/prescribing-policies-states-confront-opioid-overdose-epidemic.aspx. Accessed January 27, 2020.

35. Dworkin RH, O'Connor AB, Audette J, et al. Recommendations for the pharmacological management of neuropathic pain: an overview and literature update. Mayo Clin Proc. 2010;85(3 Suppl):S3-S14.

36. Smith RV, Boland EM, Young AM, et al. A qualitative analysis of gabapentin misuse and diversion among people who use drugs in Appalachian Kentucky. Psychol Addict Behav. 2018;32(1):115-21.

37. Lyndon A, Audrey S, Wells C, et al. Risk to heroin users of polydrug use of pregabalin or gabapentin. Addiction. 2017;112(9):1580-89.

38. Bastiaens L, Galus J, Mazur C. Abuse of gabapentin is associated with opioid addiction. Psychiatr Q. 2016;87(4):763-67.

39. Baird CRW, Fox P, Colvin LA. Gabapentinoid abuse in order to potentiate the effect of methadone: a survey among substance misusers. Eur Addict Res. 2014;20(3):115-18.

40. Centers for Medicare $\&$ Medicaid Services. Advance notice of methodological changes for calendar year (CY) 2019 for Medicare Advantage (MA) capitation rates, Part C and Part D payment policies and 2019 draft call letter. February 1, 2018. Available at: https://www.cms.gov/Medicare/HealthPlans/MedicareAdvtgSpecRateStats/Downloads/Advance2019Part2.pdf. Accessed January 27, 2020.

41. Finnerup NB, Attal N, Haroutounian S, et al. Pharmacotherapy for neuropathic pain in adults: a systematic review and meta-analysis. Lancet Neurol. 2015;14(2):162-73. 